Article

\title{
Overexpression of the DEAD-Box RNA Helicase Gene AtRH17 Confers Tolerance to Salt Stress in Arabidopsis
}

\author{
Linh Vu Nguyen ${ }^{\dagger}$, Hye-Yeon Seok ${ }^{\dagger}$, Dong-Hyuk Woo, Sun-Young Lee and Yong-Hwan Moon \\ Department of Integrated Biological Sciences, Pusan National University, Busan 46241, Korea; \\ nhqdkr@gmail.com (L.V.N.); peachworld6@gmail.com (H.-Y.S.); humblewoo@hanmail.net (D.-H.W.); \\ symoonlee@gmail.com (S.-Y.L.) \\ * Correspondence: moonyh@pusan.ac.kr; Tel.: +82-51-510-2592 \\ + The authors contributed equally to this work.
}

Received: 31 October 2018; Accepted: 26 November 2018; Published: 28 November 2018

\begin{abstract}
Plants adapt to abiotic stresses by complex mechanisms involving various stress-responsive genes. Here, we identified a DEAD-box RNA helicase (RH) gene, AtRH17, in Arabidopsis, involved in salt-stress responses using activation tagging, a useful technique for isolating novel stress-responsive genes. AT895, an activation tagging line, was more tolerant than wild type (WT) under $\mathrm{NaCl}$ treatment during germination and seedling development, and AtRH17 was activated in AT895. AtRH17 possesses nine well-conserved motifs of DEAD-box RHs, consisting of motifs Q, I, Ia, Ib, and II-VI. Although at least 12 orthologs of AtRH17 have been found in various plant species, no paralog occurs in Arabidopsis. AtRH17 protein is subcellularily localized in the nucleus. AtRH17-overexpressing transgenic plants (OXs) were more tolerant to high concentrations of $\mathrm{NaCl}$ and $\mathrm{LiCl}$ compared with WT, but no differences from WT were detected among seedlings exposed to mannitol and freezing treatments. Moreover, in the mature plant stage, AtRH17 OXs were also more tolerant to $\mathrm{NaCl}$ than $\mathrm{WT}$, but not to drought, suggesting that AtRH17 is involved specifically in the salt-stress response. Notably, transcriptions of well-known abscisic acid (ABA)-dependent and ABA-independent stress-response genes were similar or lower in AtRH17 OXs than WT under salt-stress treatments. Taken together, our findings suggest that AtRH17, a nuclear DEAD-box RH protein, is involved in salt-stress tolerance, and that its overexpression confers salt-stress tolerance via a pathway other than the well-known ABA-dependent and ABA-independent pathways.
\end{abstract}

Keywords: activation tagging line; Arabidopsis; AtRH17; DEAD-box RNA helicase; overexpression; salt stress

\section{Introduction}

Adverse abiotic stresses, such as high salinity, drought, extreme temperature, and excessive light limit growth, development, and productivity in plants. Plants show dynamic responses to adapt to those abiotic stresses at the biochemical, physiological, and molecular levels, thus enabling them to survive under variable abiotic stress conditions [1]. Adaptation to abiotic stresses requires coordinated modulations in plant metabolism, cell growth, division, and differentiation, all of which are dependent on gene control systems that are regulated by complex mechanisms [2].

RNA helicases (RHs) are ubiquitous proteins and essential conserved enzymes that function in both prokaryotes and eukaryotes [3,4]. RHs are divided into six superfamilies (SF1-SF6) depending on their specific motif sequences and domain structures, and SF2, the largest RH superfamily, mainly comprises the DEAD-box RHs [3,4]. In plants, 58 and 62 DEAD-box RHs have been identified in Arabidopsis (Arabidopsis thaliana) and in rice (Oryza sativa), respectively, to date [4-7]. 
DEAD-box RHs harbor nine conserved motifs (Q, I, Ia, Ib, and II-VI), and consist of 400-700 aa [3,8-10]. Motif $\mathrm{Q}$ regulates adenosine triphosphate (ATP) binding and hydrolysis; motif I (also known as the Walker A motif) is involved in the interaction between the ATP and $\mathrm{Mg}^{2+}$ ion; motif Ia forms a groove to bind to single-stranded DNA/RNA; motif II (otherwise known as the Walker B motif or DEAD motif) interacts with $\mathrm{Mg}^{2+}$ ion; motif III functions in NTPase and helicase activities and is responsible for RNA unwinding; and motif VI, part of ATP-binding cleft, is involved in helicase and NTPase activities. The molecular functions of motifs $\mathrm{Ib}, \mathrm{IV}$, and $\mathrm{V}$ remain unclear $[4,5]$. The "DEAD-box" designation is due to the presence of the conserved protein sequence Asp-Glu-Ala-Asp (D-E-A-D) in motif II [9-11], a sequence that is characteristic of DEAD-boxes. In addition to these conserved motifs, there are also $\mathrm{N}$-terminal and C-terminal extended regions in each DEAD-box protein that vary widely in terms of their size and composition; it has been proposed that they function as substrate-binding specificities or as subcellular localization signals, or possibly that they interact with accessory components [12-14]. For example, a nucleoside triphosphate (NTP)-binding motif, which is required to function in an ATP-dependent manner, is found in all DEAD-box RHs [4,5].

DEAD-box RHs have been implicated in RNA synthesis, modification, cleavage, and degradation, as well as in ribosome biogenesis and translation initiation [4]. Moreover, they are also involved in the ATP-dependent rearrangement of intermolecular and intramolecular RNA structures or remodeling of ribonucleoprotein complexes [4,5,15]. In Arabidopsis, AtRH3, AtRH22/HS3, and AtRH39, for instance, encode chloroplastic DEAD-box RHs, and they are associated with RNA splicing and ribosomal RNA (rRNA) maturation [16-19]. AtRH38/LOS4 plays an essential role in the exporting of RNA from the nucleus to the cytoplasm [16,20]. AtRH14, AtRH20, AtRH30, and AtRH40 are involved in nonsense RNA decay and ribosome biogenesis [21]. In rice, OsRH2 and OsRH34 are core components of the exon junction complex, which play important roles in gene expression [22].

Despite their sequences and structural similarities, each DEAD-box RH is thought to have different functions in plant development $[10,23]$. In Arabidopsis, for instance, loss-of-function mutants of AtRH3, AtRH22/HS3, or AtRH39 cause abnormal chloroplast development and pale-green seedling phenotypes [16-19]. AtRH47/ISE1 affects embryonic development [24]; AtRH36/SWA3 is required for the proper development of the female gametophyte [25,26]; and AtRH57 responds to sugar involving glucose-mediated abscisic acid (ABA)-dependent inhibition of germination and seedling development [27]. In rice, OsRH15/AIP2 and OsRH56/AIP1 regulate programmed cell death during tapetum degeneration [28]. In addition, a number of DEAD-box RHs play important roles in plant abiotic stress tolerance via their functions in specific RNA processing events [29,30]. It has been demonstrated that Arabidopsis AtRH38/LOS4 regulates the expression of DREB/CBFs under chilling stress [16,31]; AtRH7 and AtRH42/RCF1 are up-regulated under cold-stress conditions. In addition, atrh7 and atrh42/rcf1 mutants are more sensitive to cold stress than wild type (WT), whereas AtRH42/RCF1 OXs are more tolerant to cold stress than WT [32,33]. The expression of STRS1 and STRS2 genes in Arabidopsis are rapidly down-regulated by various stresses and by ABA, and mutants exhibit a significant increase in salt-, osmotic-, and heat-stress tolerances, as well as enhanced expression of stress-inducible genes [34,35]. AtRH5, AtRH9, and AtRH25, three DEAD-box RHs in Arabidopsis, respond to multiple abiotic stresses [36]. In rice, OsRH50/OsBIRH1 has been reported to function in modulating defense responses against pathogenic infections and oxidative stress [37]. Ectopic expression of PDH45, a DEAD-box RH in pea (Pisum sativum), improves salt tolerance in rice and tobacco (Nicotiana tacum), and ectopic expression of PDH47, another pea DEAD-box RH, enhances drought tolerance in rice $[38,39]$.

In the present study, we used an activation tagging system to identify novel salt-stress-responsive genes in Arabidopsis. The activation tagging system makes it possible to identify genes which have a functional redundancy, or those for which loss-of-function mutants show lethality [40-43]. In addition, activated phenotypes can be observed directly without the generation of OXs [40-43]. We isolated 
AtRH17, a DEAD-box RH gene, using an activation tagging approach, and demonstrated that AtRH17 is involved in salt-stress tolerance as a nuclear protein in Arabidopsis.

\section{Results}

\subsection{Isolation of AtRH17 via Activation Tagging}

To isolate novel salt-stress-responsive genes, we screened $\mathrm{T}_{1}$ activation tagging lines of Arabidopsis harboring pFGL942, an activation tagging vector containing four copies of cauliflower mosaic virus $(C a M V) 35 S$ enhancers (Supplementary Figure S1a), as described previously [43]. Through primary and secondary screening using $\mathrm{T}_{2}$ plants, we isolated the AT895 line, which exhibited a salt-tolerant phenotype during germination (Supplementary Figure S1b,c). For further experiments, we isolated homozygotes of the AT895 line, and then analyzed the salt-stress response of the AT895 line at the seedling stage. To validate the isolated line, $\mathrm{T}_{3}$ seedlings of the AT895 line were transferred onto 0 , 150, and $160 \mathrm{mM} \mathrm{NaCl-containing} \mathrm{Murashige} \mathrm{and} \mathrm{Skoog} \mathrm{(MS)} \mathrm{agar} \mathrm{media.} \mathrm{As} \mathrm{a} \mathrm{result,} \mathrm{AT895} \mathrm{line}$ seedlings were more tolerant and showed higher fresh weight (FW) than WT seedlings under 150 and $160 \mathrm{mM} \mathrm{NaCl}$ treatment conditions (Figure 1a,b), suggesting that the AT895 line is more tolerant to salt stress than WT during both germination and seedling development.

(a)

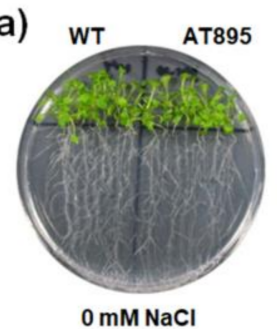

(c)

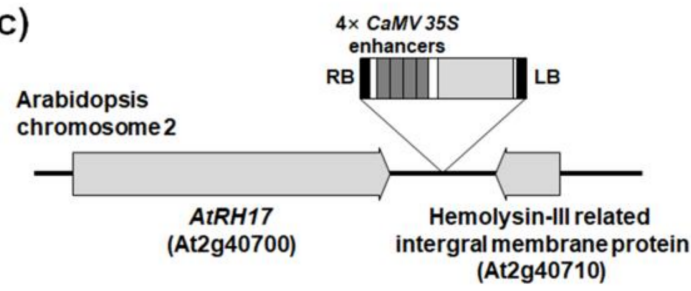

(b)

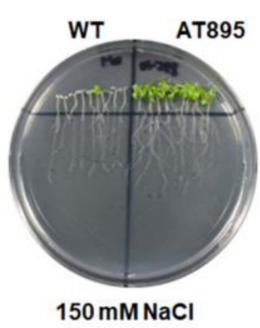

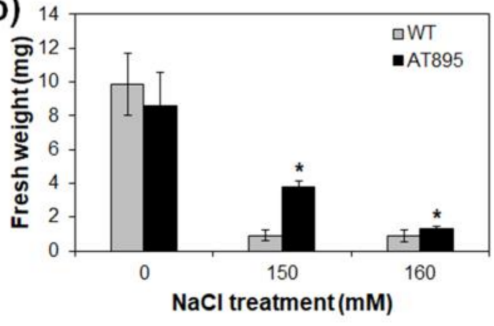

(d)

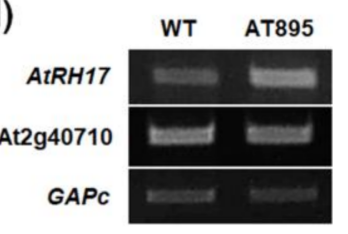

Figure 1. Isolation of the AtRH17 gene involved in salt-stress tolerance from activation tagging line analysis. (a,b) Responses of wild type (WT) and AT895 seedlings to 0, 150, and $160 \mathrm{mM} \mathrm{NaCl}$. Seven-day-old seedlings were transferred onto NaCl-containing Murashige and Skoog (MS) agar media, and photographs were taken seven days after $\mathrm{NaCl}$ treatment. Fresh weight (FW) was measured seven days after $\mathrm{NaCl}$ treatment. In (b), error bars represent standard deviation ( $n=30$ plants) and * indicate $t$-test $p<0.05$. (c) Schematic map of the T-DNA insertion position in the genomic DNA of AT895. (d) Expression analysis of AtRH17 (At2g40700) and hemolysin-III related integral membrane protein gene (At2g40710) in the AT895 plants by semi-quantitative reverse transcription (RT)-PCR. GAPc was used as an internal control.

To identify the T-DNA tagging site in the AT895 line, we extracted genomic DNA from AT895 plants and performed a thermal asymmetric interlaced (TAIL)-PCR. Sequencing analysis using amplified PCR fragments revealed that CaMV 35S enhancers were inserted between At2g40700 and At2g40710 on Arabidopsis chromosome 2 (Figure 1c). At2g40700 encodes AtRH17, a DEAD-box RH, whereas At2g40710 encodes a hemolysin-III related integral membrane protein. We analyzed transcript levels of At2g40700 and At2g40710 in $\mathrm{T}_{2}$ plants of the AT895 line using semi-quantitative reverse transcription (RT)-PCR to identify a gene activated by CaMV $35 S$ enhancers. This analysis revealed that At2g40700 transcription was higher in the AT895 line than WT, whereas no significant differences 
were detected in At2g40710 transcription between the AT895 line and WT (Figure 1d), implying that AtRH17 is activated in the AT895 line.

\subsection{Phylogenetic Analysis of AtRH17}

DEAD-box RHs have been found in most prokaryotes and all eukaryotes, including plants [4-6]. To analyze conserved motifs in AtRH17, we performed multiple alignments of AtRH17 and its 12 orthologs in nine species exhibiting high similarity with AtRH17 using amino acid sequences of the entire open reading frame (ORF), and found that all 13 proteins possessed the well-conserved nine motifs characteristic of DEAD-box RHs, such as Q, I, Ia, Ib, and II-VI (Figure 2a). In addition, BlastP analysis using the entire ORF of AtRH17 showed no paralog of AtRH17 among the other 57 DEAD-box RHs present in Arabidopsis (data not shown).
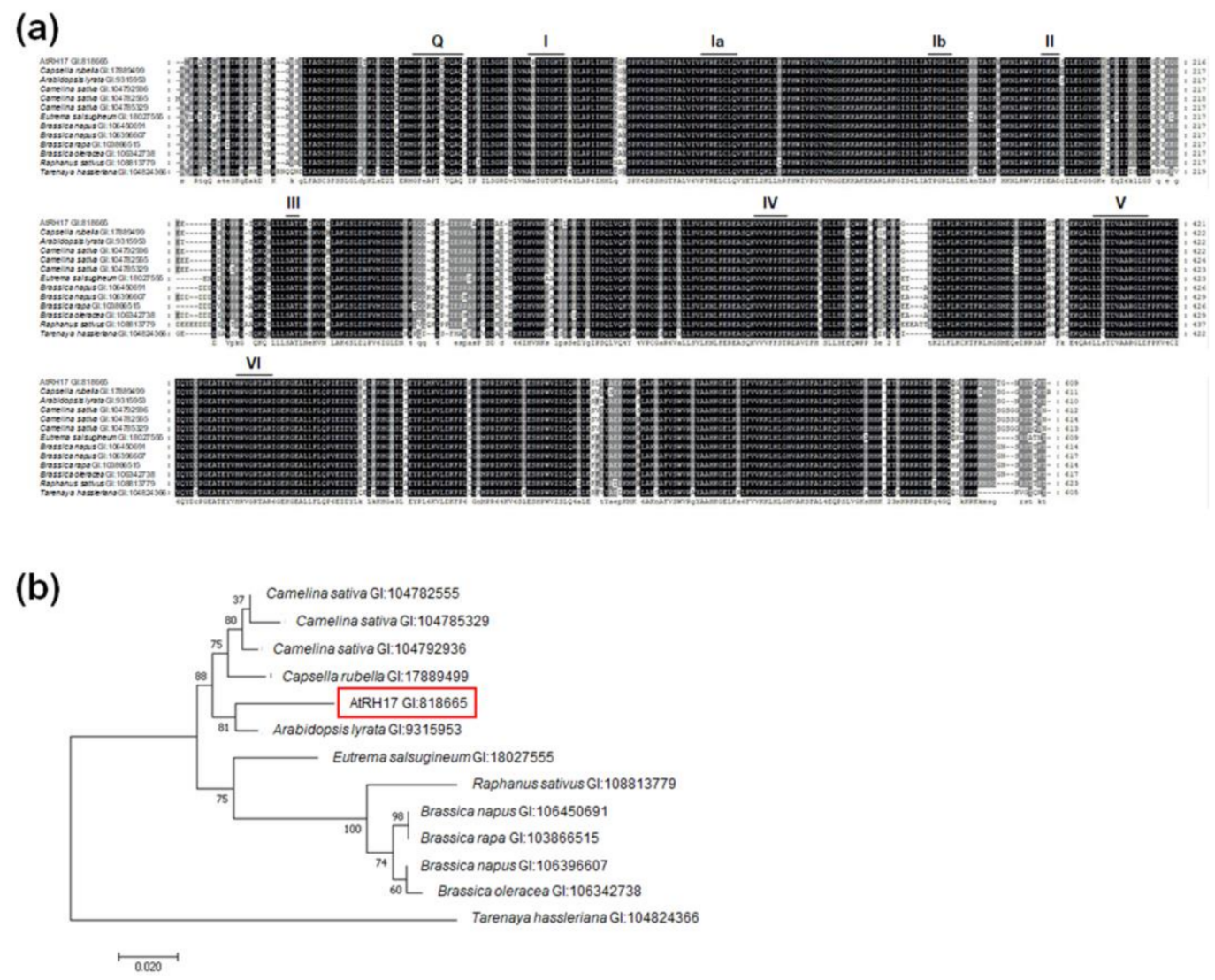

Figure 2. Conservation of DEAD-box RNA helicase (RH) motifs between AtRH17 and its 12 orthologs. (a) Multiple sequence alignment was carried out with amino acid sequences of the entire open reading frames (ORFs) of AtRH17 and the 12 orthologs using ClustalX 2.1 program. The gene ID number of each protein sequence is as follows: AtRH17: 818665; Capsella rubella: 17889499; Arabidopsis lyrata: 9315953; Camelina sativa: 104792936, 104782555, 104785329; Eutrema salsugineum: 18027555; Brassica napus: 106450691, 106396607; Brassica rapa: 103866515; Brassica oleracea: 106342738; Raphanus sativus: 108813779; Tarenaya hassleriana: 104824366. (b) Molecular phylogenetic tree of AtRH17 and the 12 orthologs was generated with the conserved regions including the well-conserved nine motifs (48-442 aa in AtRH17) using Maximum Likelihood method in MEGA 7.0.26 software. The number on each node indicates the bootstrap value for 1000 replicates.

We generated a phylogenetic tree to compare the phylogenetic relationship between AtRH17 and the 12 orthologs. The alignment of the conserved regions, including the well-conserved nine motifs (48-442 aa in AtRH17), revealed that AtRH17 is the most similar to the DEAD-box RH gene found in A. lyrata (Figure 2b). 


\subsection{Subcellular Localization of AtRH17 in the Nucleus}

To investigate the subcellular localization of AtRH17, we transformed Arabidopsis protoplasts with synthetic green fluorescent protein (sGFP)-AtRH17 and AtRH17-sGFP fusion constructs (Figure 3a). We observed that the GFP signals of both sGFP-AtRH17 and AtRH17-sGFP constructs were in the nucleus, in which the GFP signals overlapped with 4',6-diamidino-2-phenylindole (DAPI) signals (Figure 3b), indicating that AtRH17 functions in the nucleus.

(a)

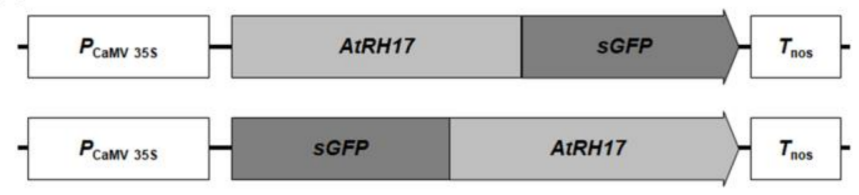

(b)

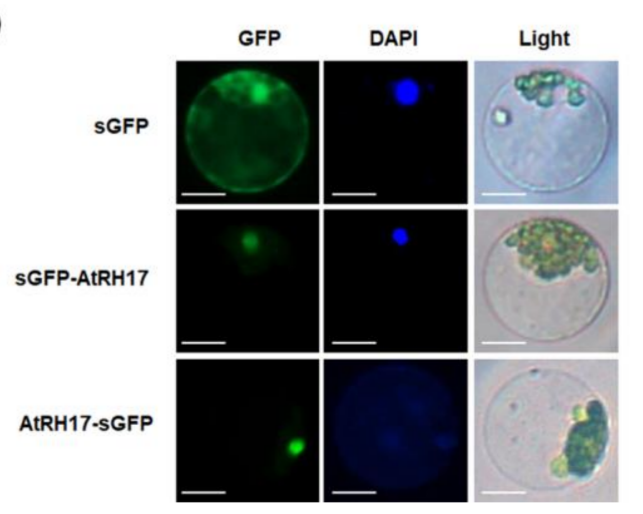

Figure 3. Investigation of the subcellular localization of AtRH17 in Arabidopsis protoplasts. (a) Schematic maps of the entire ORF of AtRH17 constructs fused to C-terminal or N-terminal synthetic green fluorescent protein (sGFP). (b) The subcellular localization of AtRH17 protein was examined by transient expression in Arabidopsis protoplasts. Left, GFP signal; middle, 4',6-diamidino-2-phenylindole (DAPI) staining; right, light microscopic picture. Scale bars represent $10 \mu \mathrm{m}$.

\subsection{Expression of AtRH17 Is Unaffected by Osmotic Stress Conditions}

Because the salt tolerance of the AT895 line strongly suggested that AtRH17 could be related to osmotic stress response in Arabidopsis, we examined the expression patterns of AtRH17 under osmotic-stress conditions, including $\mathrm{NaCl}$, mannitol, and ABA treatments. Quantitative RT-PCR analysis using 10-day-old WT seedlings treated with $300 \mathrm{mM} \mathrm{NaCl}, 300 \mathrm{mM}$ mannitol, and $100 \mu \mathrm{M}$ ABA revealed that transcript levels of AtRH17 were not significantly different after $\mathrm{NaCl}$, mannitol, and ABA treatments compared with stress-free conditions (Figure $4 \mathrm{a}-\mathrm{c}$ ). The proper treatments of $\mathrm{NaCl}$, mannitol, and ABA were confirmed by $R D 29 A$ expression (Figure $4 \mathrm{~d}-\mathrm{f}$ ). Semi-quantitative RT-PCR analysis produced similar results, in which AtRH17 exhibited similar transcript levels before and after the $\mathrm{NaCl}$, mannitol, and ABA treatments (Supplementary Figure S2). 
(a)

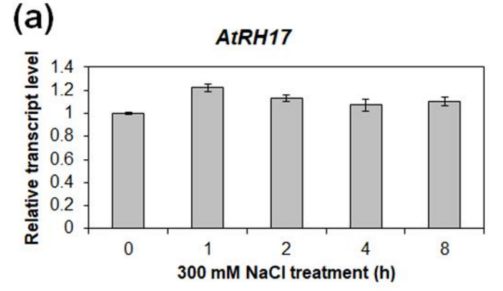

(d)

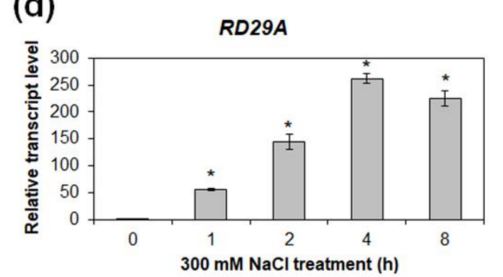

(b)

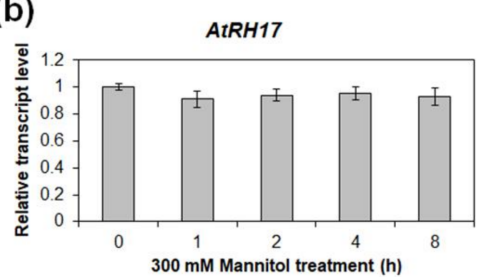

(e)

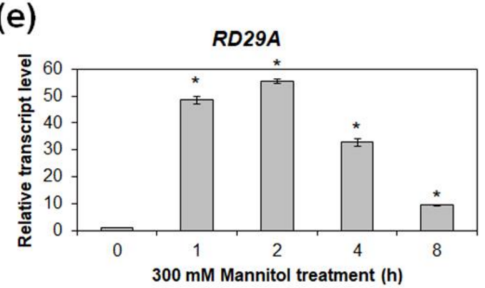

(c)

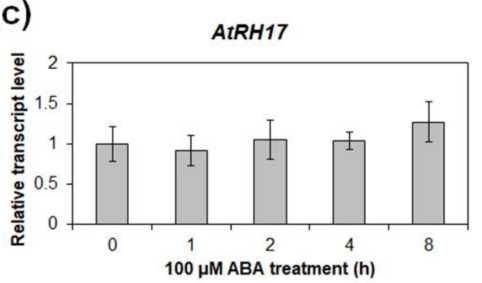

(f)

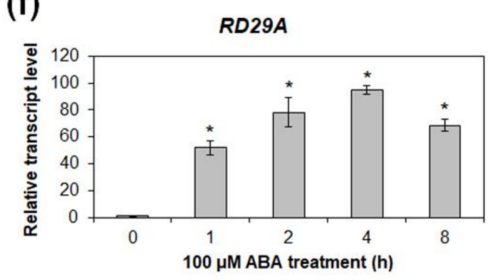

Figure 4. Expression analysis of $A t R H 17$ under osmotic-stress conditions. (a,d) Quantitative RT-PCR analysis of AtRH17 (a) and RD29A (d) under $300 \mathrm{mM} \mathrm{NaCl}$ treatment for 0, 1, 2, 4, and $8 \mathrm{~h}$. $(\mathbf{b}, \mathbf{e})$ Quantitative RT-PCR analysis of AtRH17 (b) and RD29A (e) under $300 \mathrm{mM}$ mannitol treatment for $0,1,2,4$, and $8 \mathrm{~h}$. (c,f) Quantitative RT-PCR analysis of AtRH17 (c) and RD29A (f) under $100 \mu \mathrm{M}$ abscisic acid (ABA) treatment for 0, 1, 2, 4, and $8 \mathrm{~h}$. RD29A was used as a control for $\mathrm{NaCl}$, mannitol, and ABA treatments. GAPc was used as an internal control. Transcript levels at $0 \mathrm{~h}$ were set as 1. Three independent reactions were performed for each technical replicate. Two technical replicates were performed for each biological replicate. At least two biological replicates showed similar results, with one shown here. Error bars represent standard deviation ( $n=6$ reactions) and ${ }^{*}$ indicate $t$-test $p<0.05$.

\subsection{Expression of AtRH17 during Developmental Stages and in Organs}

Spatial and temporal expression patterns of AtRH17 were investigated in Arabidopsis by quantitative RT-PCR. Transcript levels of AtRH17 increased as plant developed from 4 to 21 days after germination (DAG) (Figure 5a). In mature plants, AtRH17 transcription was highest in cauline leaves compared to other organs examined, such as siliques, roots, rosette leaves, stems, and floral clusters (Figure 5b). Semi-quantitative RT-PCR analysis showed similar results to those of the quantitative RT-PCR analysis (Supplementary Figure S3).

(a)

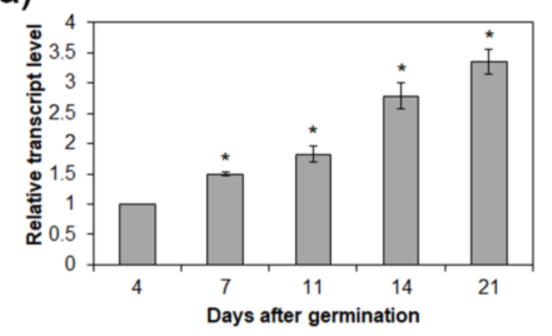

(b)

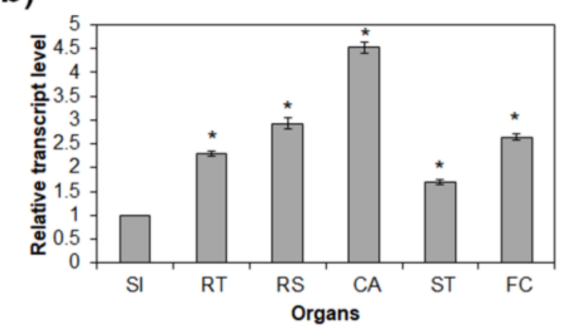

Figure 5. Temporal and spatial expression patterns of AtRH17. (a) Quantitative RT-PCR analysis of AtRH17 in 4-, 7-, 11-, 14-, and 21-day-old WT seedlings grown under short-day (SD) conditions. $G A P C$ was used as an internal control. Transcript level at 4 days after germination (DAG) was set as 1. (b) Quantitative RT-PCR analysis of AtRH17 expression in organs of 36-day-old mature WT grown under long-day (LD) conditions. GAPc was used as an internal control. Transcript level in SI was set as 1. SI, siliques; RT, roots; RS, rosette leaves; CA, cauline leaves; ST, stems; FC, floral clusters. Three independent reactions were performed for each technical replicate. Two technical replicates were performed for each biological replicate. At least two biological replicates showed similar results, with one shown here. Error bars represent standard deviation $\left(n=6\right.$ reactions) and ${ }^{*}$ indicate $t$-test $p<0.05$. 


\subsection{AtRH17 OXs Exhibit Tolerance to Salt Stresses, but Not to Mannitol and Freezing Stresses}

To analyze the functional roles of $A t R H 17$ in abiotic stress response, we generated AtRH17 OXs (Figure 6a) and selected three independent $\mathrm{T}_{1}$ lines that had higher levels of AtRH17 expression than WT (Figure 6b,c). Similar to the AT895 line, AtRH17 OX seedlings showed more tolerant phenotypes, with higher FW than WT seedlings under 150 and $160 \mathrm{mM} \mathrm{NaCl}$ treatments (Figure 6d,e and Supplementary Figure S4). Evaluations of Photosystem II (PS II) activity are commonly used to examine the physiology of plants under salt-stress conditions [44]. We measured PS II activity, represented by $F_{v} / F_{m}$, in both $A t R H 17$ OX and WT plants. Under 150 and $160 \mathrm{mM} \mathrm{NaCl}$ treatments, $F_{v} / F_{m}$ levels were significantly higher in AtRH17 OXs than in WT (Figure 6f,g). Moreover, AtRH17 OX seedlings displayed greater tolerance than WT under 20 and $25 \mathrm{mM} \mathrm{LiCl}$ treatments (Figure 6h,i). In addition, we measured the production of superoxide in AtRH17 OXs under stress conditions because reactive oxygen species (ROS) production is usually enhanced in plants experiencing abiotic stresses [45], and found that superoxide production was significantly lower in AtRH17 OXs than in WT under 50 and $100 \mathrm{mM} \mathrm{NaCl}$ treatments (Figure 6j), suggesting that the lower superoxide accumulation in AtRH17 OXs compared to WT might be a contributing factor to the greater salt-stress tolerance displayed by AtRH17 OXs.

Because salt stress typically results in osmotic stress [46], we assessed the response of AtRH17 OXs to mannitol treatment, another source of osmotic stress, and found that there were no significant differences between AtRH17 OX and WT seedlings under 400, 450, and $500 \mathrm{mM}$ mannitol conditions (Figure 6k,1). We also examined the cold-stress response of AtRH17 OXs. Three-week-old AtRH17 OXs and WT on MS agar media were kept at $-8^{\circ} \mathrm{C}$. No significant differences were detected between AtRH17 OX and WT seedlings following freezing treatment (Supplementary Figure S5). These results indicated that AtRH17 OXs are no more tolerant to mannitol and freezing stresses than WT.

Next, we investigated the salt-stress response of AtRH17 OXs at mature plants stage. To this end, 3-week-old AtRH17 OXs and WT were treated with 0, 350, and $400 \mathrm{mM} \mathrm{NaCl}$ solutions for three weeks. We then determined the survival ratio, PS II activity, and chlorophyll contents of AtRH17 OXs and WT under both $\mathrm{NaCl}$-free conditions and following $\mathrm{NaCl}$ treatments. No significant differences were detected between AtRH17 OXs and WT under NaCl-free conditions, but AtRH17 OXs were more tolerant and had higher survival ratios than WT in the 350 and $400 \mathrm{mM} \mathrm{NaCl}$ treatments (Figure 7a,b). The PS II activity assessed by $F_{v} / F_{m}$ was also higher in AtRH17 OXs than WT in the 350 and $400 \mathrm{mM} \mathrm{NaCl}$ treatments (Figure 7c). In addition, higher chlorophyll contents, as represented by SPAD values, were detected in AtRH17 OXs than WT in the 350 and $400 \mathrm{mM} \mathrm{NaCl}$ treatments (Figure 7d), demonstrating that mature AtRH17 OXs are more tolerant than WT under salt-stress conditions. Moreover, to confirm the osmotic-stress response of AtRH17 OXs at mature plant stage, we treated drought stress to mature AtRH17 OXs, and then determined the survival ratio, PS II activity, and chlorophyll contents of AtRH17 OXs and WT under both drought-free conditions, and following drought treatments. No significant differences were detected between AtRH17 OXs and WT under both drought-free conditions and following drought treatments (Supplementary Figure S6). Taken together, our results suggested that overexpression of AtRH17 confers tolerance to salt stress specifically, and at both the seedling and mature plant stages. 
(a)<smiles>[10BH]</smiles>

$P_{\text {car }}$

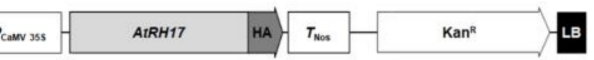

(d)

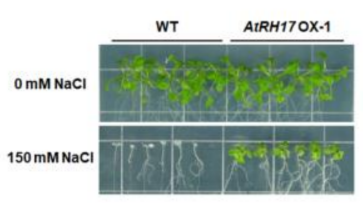

(e)

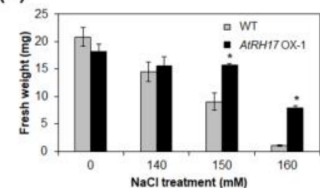

(h)

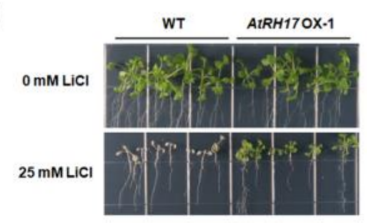

(k)

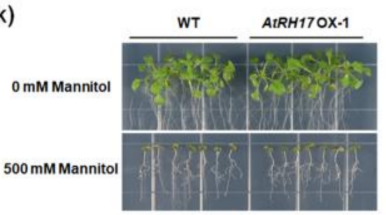

(i)

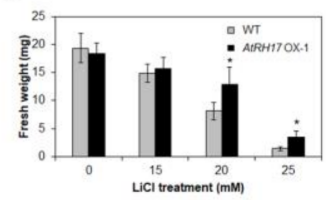

(I)

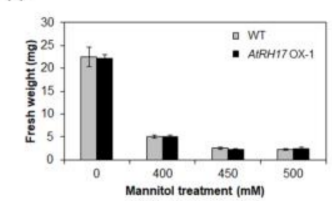

(b)

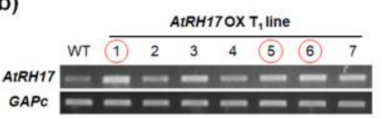

(f)

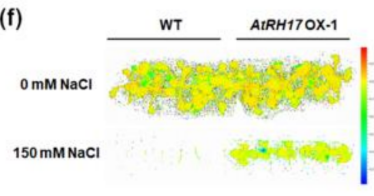

(g)

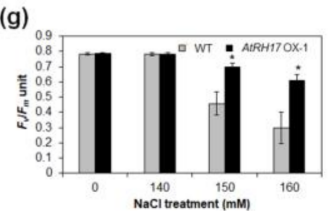

(c)

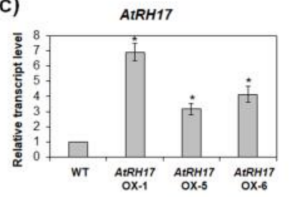

(j)

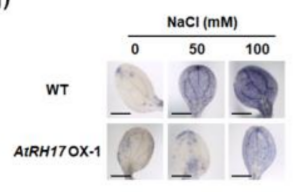

Figure 6. Osmotic-stress response of AtRH17-overexpressing transgenic plant (OX) seedlings. (a) Schematic map of vector for overexpression of AtRH17. (b) Selection of $\mathrm{T}_{1}$ lines overexpressing AtRH17 by semi-quantitative RT-PCR analysis. Circled lines were selected for further analysis. GAPC was used as an internal control. (c) The transcript levels of AtRH17 in AtRH17 OXs were determined by quantitative RT-PCR analysis. GAPC was used as an internal control. Transcript level in WT was set as 1. Three independent reactions were performed for each technical replicate. Two technical replicates were performed for each biological replicate. Error bars represent standard deviation ( $n=6$ reactions) and * indicate $t$-test $p<0.05$. (d) Responses of WT and AtRH17 OX-1 T 3 seedlings to 0, 140, 150, and $160 \mathrm{mM} \mathrm{NaCl}$. Five-day-old seedlings were transferred onto NaCl-containing MS agar media and photographs were taken 15 days after $\mathrm{NaCl}$ treatments. (e) $\mathrm{FW}$ was measured 15 days after $\mathrm{NaCl}$ treatments. (f) Fluorescent image of Photosystem (PS) II activity $\left(F_{v} / F_{m}\right)$ was taken 15 days after $\mathrm{NaCl}$ treatments. (g) PS II activity $\left(F_{v} / F_{m}\right)$ was measured 15 days after $\mathrm{NaCl}$ treatments using FluorCam. (h) Responses of WT and AtRH17 OX-1 $\mathrm{T}_{3}$ seedlings to 0, 15, 20, and $25 \mathrm{mM} \mathrm{LiCl}$. Five-day-old seedlings were transferred onto $\mathrm{LiCl}$-containing MS agar media and photographs were taken 15 days after $\mathrm{LiCl}$ treatments. (i) $\mathrm{FW}$ was measured 15 days after $\mathrm{LiCl}$ treatments. (j) Superoxide accumulations in cotyledons of 7-day-old WT and AtRH17 OX-1 seedlings were detected by nitro blue tetrazolium (NBT) staining after $2 \mathrm{~h} \mathrm{NaCl}$ treatments. Scale bars represent $2 \mathrm{~mm}$. (k) Responses of WT and AtRH17 OX-1 $\mathrm{T}_{3}$ seedlings to $0,400,450$, and $500 \mathrm{mM}$ mannitol. Five-day-old seedlings were transferred onto mannitol-containing MS agar media and photographs were taken 16 days after mannitol treatments. (1) FW was measured 16 days after mannitol treatments. In $(\mathbf{e}, \mathbf{g}, \mathbf{i}, \mathbf{1})$, error bars represent standard deviation ( $n=35$ plants) and * indicate $t$-test $p<0.05$. Three independent $T_{1}$ lines showed similar results, with one shown here. 
(a)

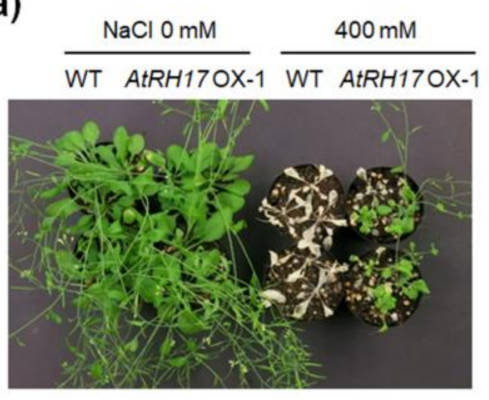

(c)

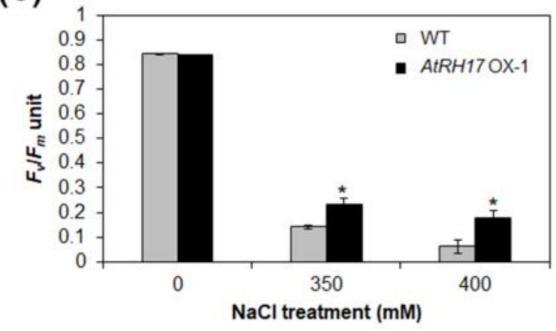

(b)

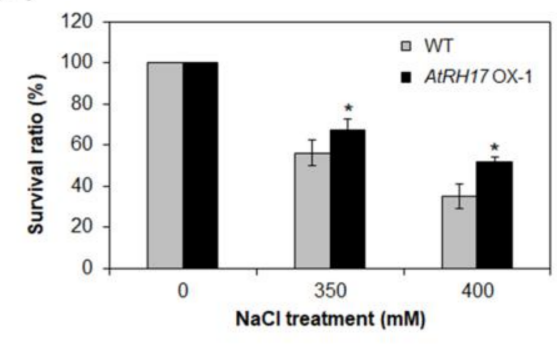

(d)

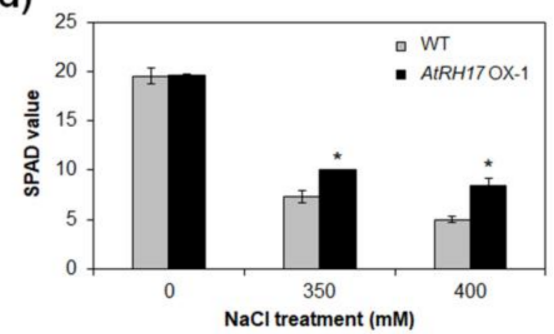

Figure 7. Salt-stress response of AtRH17 OX mature plants. (a) Three-week-old WT and AtRH17 OX-1 plants were watered with 0,350 , and $400 \mathrm{mM} \mathrm{NaCl}$. Photograph was taken after 20-day $\mathrm{NaCl}$ treatments. (b) Survival ratio of WT and AtRH17 OX-1 treated with 0, 350, and $400 \mathrm{mM} \mathrm{NaCl}$ for 20 days. (c) PS II activity $\left(F_{v} / F_{m}\right)$ of WT and AtRH17 OX-1 treated with 0,350 , and $400 \mathrm{mM} \mathrm{NaCl}$ for 17 days. (d) SPAD values of WT and AtRH17 OX-1 treated with 0, 350, and $400 \mathrm{mM} \mathrm{NaCl}$ for 17 days. Error bars represent standard deviation $\left(n=30\right.$ plants) and ${ }^{*}$ indicate $t$-test $p<0.05$. Three independent $\mathrm{T}_{1}$ lines showed similar results, with one shown here.

2.7. Expression of ABA-Dependent and ABA-Independent Salt-Stress-Responsive Genes Does Not Alter, but is Lower in AtRH17 OXs under Salt Stress Conditions

Plant response to salt stress is usually mediated by ABA-dependent and/or ABA-independent signaling pathways [47]. To verify whether AtRH17 is involved in ABA-dependent or ABA-independent salt-stress signal pathways, we examined the expression of ABA-dependent and ABA-independent salt-stress-responsive genes in AtRH17 OXs under salt-stress conditions. Quantitative RT-PCR analysis using 10-day-old seedlings treated with $150 \mathrm{mM} \mathrm{NaCl}$ revealed that the expression of AtRH17 was increased in AtRH17 OXs after $\mathrm{NaCl}$ treatment, whereas the expression of AtRH17 was not significantly changed in WT after $\mathrm{NaCl}$ treatment (Figure 8a). Expression of all the ABA-dependent or ABA-independent salt-stress-responsive genes, such as $R D 29 A, R A B 18, R D 29 B$, RD22, COR47, DREB2A, and DREB2B, were elevated in AtRH17 OXs under $\mathrm{NaCl}$ treatment. Notably, the transcription levels of all those genes were lower in $A t R H 17$ OXs than WT after $\mathrm{NaCl}$ treatment (Figure 8b-h), suggesting that overexpressed AtRH17 inhibits the increase of those stress-responsive genes' transcriptions. Our results indicated that salt-stress tolerance of AtRH17 OXs is mediated by a pathway or mechanism other than the well-known ABA-dependent and ABA-independent stress-responsive pathways. 
(a)

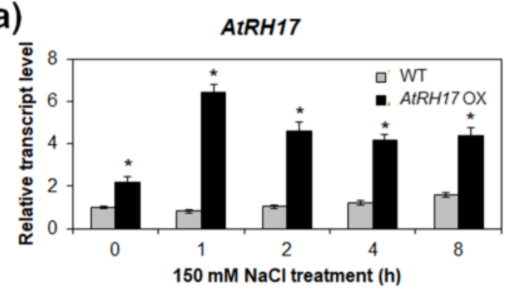

(c)

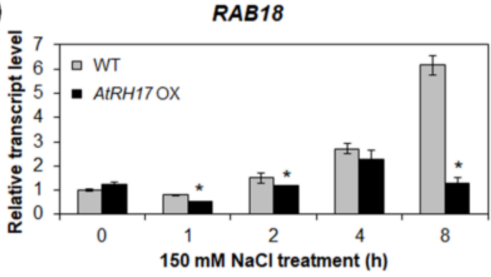

(e)

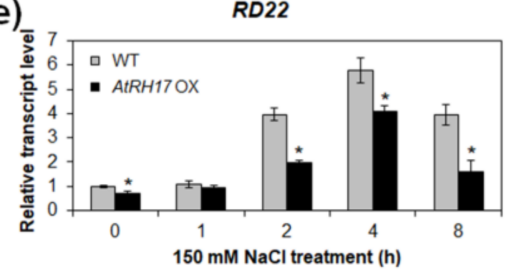

(g)

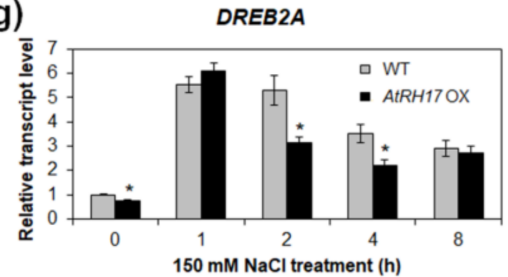

(b)

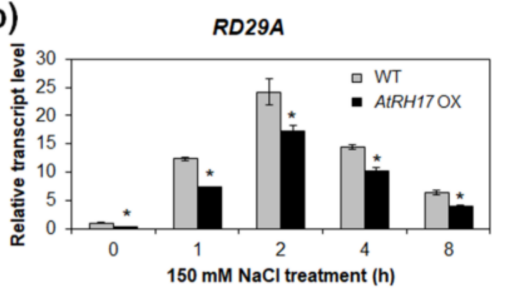

(d)

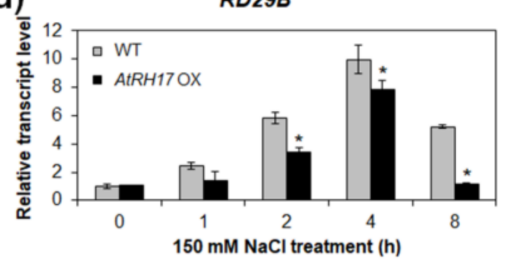

(f)

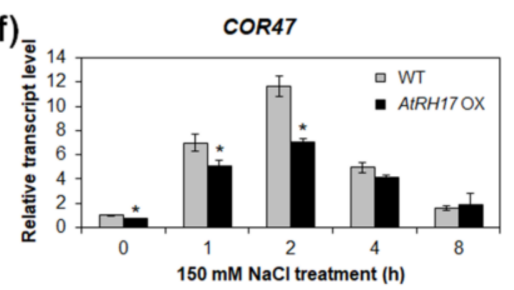

(h)

DREB2B

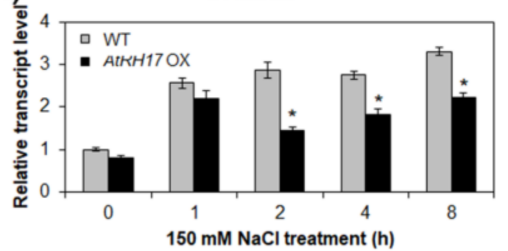

Figure 8. Expression patterns of ABA-dependent and ABA-independent salt-stress-responsive genes in AtRH17 OXs. Quantitative RT-PCR analysis of AtRH17 (a), RD29A (b), RAB18 (c), RD29B (d), RD22 (e), COR47 (f), DREB2A (g), and DREB2B (h) in WT and AtRH17 OX seedlings under $150 \mathrm{mM} \mathrm{NaCl}$ treatment for $0,1,2,4$, and $8 \mathrm{~h}$. GAPc was used as an internal control. Transcript levels at $0 \mathrm{~h}$ in WT were set as 1 . Three independent reactions were performed for each technical replicate. Two technical replicates were performed for each biological replicate. At least two biological replicates showed similar results, with one shown here. Error bars represent standard deviation $(n=6$ reactions) and * indicate $t$-test $p<0.05$.

\section{Discussion}

Activation tagging is useful for isolating novel stress-responsive genes, and makes it possible to study genes that have functional redundancy or for which loss-of-function mutants demonstrate lethality [40-43]. In the present study, we isolated AtRH17, an Arabidopsis DEAD-box RH gene, involved in salt-stress response, using an activation tagging system. DEAD-box RHs have nine conserved motifs with the D-E-A-D sequence in motif II [3,8-10], and they have functional roles in RNA synthesis and processing, ribosome biogenesis, the initiation of translation, and the regulation of riboprotein complexes $[4,8,48]$. AtRH17 has orthologs in other plant species with well-conserved nine motifs (Figure 2a), but, interestingly, it does not have a paralog, indicating that AtRH17 may have unique role in Arabidopsis. Because AtRH17 transcription does not increase under salt treatment, it might be very difficult to isolate AtRH17 by expression analysis such as microarray or RNA-seq, demonstrating that the activation tagging system is useful method to isolate $A t R H 17$ as a salt-stress-responsive gene. We have previously isolated S-RBP11, a small RNA-binding protein gene, and AtSFT12, a Qc-SNARE protein gene, using an activation tagging system [43,49]. 
The activation tagging line, AT895, in which AtRH17 is activated, was more tolerant to high salt stress than WT during germination and seedling development (Supplementary Figure S1 and Figure 1). In addition, AtRH17 OXs exhibited greater tolerance than WT under salt-stress conditions at both the seedling and mature plant stages (Figures 6 and 7). Superoxide accumulation was lower in AtRH17 OXs than WT (Figure 6j), which possibly contributes to the higher salt-stress tolerance of AtRH17 OXs. Moreover, AtRH17 OXs were not significantly more tolerant than WT under mannitol, freezing, and drought treatments (Figure 6 and Supplementary Figures S5 and S6), implying that AtRH17 is involved in the salt-stress response, not in osmotic- and cold-stress responses. These results indicated that the ectopic overexpression of AtRH17 contributes to salt-stress tolerance during most Arabidopsis vegetative development stages, and that $A t R H 17$ is involved specifically in the salt-stress response.

Assessment of AtRH17 expression under salt-stress and osmotic-stress conditions revealed that AtRH17 transcription was unchanged by salt treatment, nor by mannitol and ABA treatments (Figure 4 and Supplementary Figure S2). In addition, we found that AtRH17 expression increased as Arabidopsis seedlings developed (Figure 5). Because the elevated transcript level of AtRH17 in OXs can confer elevated salt tolerance, these results suggested that $A t R H 17$ potentially contributes to salt tolerance in a gradual manner as Arabidopsis seedlings develop.

The results of the expression analysis of ABA-dependent and ABA-independent salt-stress-responsive genes indicated that the expression of all of the ABA-dependent and ABA-independent salt-stress-responsive genes included in our analysis (RD29A, RAB18, RD29B, $R D 22, C O R 47, D R E B 2 A$, and DREB2B) were no higher in AtRH17 OXs than WT under salt-stress conditions; on the contrary, the expression levels of all of these genes were lower in AtRH17 OXs than WT (Figure 8), indicating that AtRH17 might function as a negative regulator of expression of those genes, and that the salt-stress tolerance of AtRH17 OXs might be mediated by some other pathway than the well-known ABA-dependent or ABA-independent stress-responsive pathways.

We determined AtRH17 to be localized in the nucleus (Figure 7). Previous research has shown that various nuclear DEAD-box RHs play functional roles in pre-rRNA processing [27], ribosome biogenesis [13], messenger RNA (mRNA) exporting [16], and RNA-directed DNA methylation [35]. In Arabidopsis, STRS1 and STRS2 are involved in epigenetic gene silencing, resulting in suppression of abiotic-stress-responsive genes [34,35]. Mutants of STRSs are more tolerant to salt, osmotic, and heat stresses, whereas STRSs OXs are more sensitive [34,35]. AtRH7/PRH75 participates in cold tolerance via regulation of CBF genes through involvement in rRNA biogenesis [32]; as such, it is possible that AtRH17 is also involved in RNA metabolism in the nucleus that regulates expression of salt-stress-responsive genes. Further studies exploring the specific molecular functions of AtRH17 are necessary.

Taken together, our results demonstrated that AtRH17, encoding a nuclear DEAD-box RH, is involved in salt-stress tolerance in Arabidopsis.

\section{Materials and Methods}

\subsection{Plant Materials and Growth Conditions}

All Arabidopsis lines used in this study were of the ecotype Columbia (Col-0). Seeds were surface-sterilized and germinated on MS agar media, as described previously [50]. Seedlings were grown under short-day (SD) ( $8 \mathrm{~h}$ light $/ 16 \mathrm{~h}$ dark) or long-day (LD) (16 h light $/ 8 \mathrm{~h}$ dark) photoperiods, with temperature maintained at $22{ }^{\circ} \mathrm{C}$.

\subsection{Plasmid Construction and Plant Transformation}

To generate a vector for AtRH17 OXs, an entire ORF of AtRH17 was cloned into pFGL1400, in which the modified CaMV $35 S$ promoter directs the constitutive expression of AtRH17 in frame following hemagglutinin (HA) [50]. 
For protein subcellular localization, the entire ORF of AtRH17 was cloned into the binary vectors pFGL1283 and pFGL1292 under the control of a modified CaMV $35 S$ promoter, in frame with $\mathrm{N}$-terminal and C-terminal sGFP, respectively. Primers used for PCR are listed in Supplementary Table S1.

All constructs were introduced into Agrobacterium tumefaciens strain GV3101 using the freeze-thaw method [51] and subsequently transformed into Arabidopsis plants using the floral-dipping method [52]. Transgenic plants were selected on MS agar media with kanamycin $(50 \mu \mathrm{g} / \mathrm{mL}) . \mathrm{T}_{3}$ or $\mathrm{T}_{4}$ homozygous lines were used for subsequent analysis.

\subsection{Activation Tagging Line Screening and Plant Stress Treatments}

Procedures for activation tagging line screening followed those described previously [43].

For RT-PCR analysis under osmotic stress conditions, 10-day-old WT seedlings grown under SD conditions were exposed to filter papers soaked with MS solution containing $300 \mathrm{mM} \mathrm{NaCl}, 300 \mathrm{mM}$ mannitol, and $100 \mu \mathrm{M}$ ABA. The seedlings were harvested separately after $1,2,4$, and $8 \mathrm{~h}$, with $0 \mathrm{~h}$ as the control. For the analysis of salt-stress-responsive gene expression under salt-stress conditions, WT and AtRH17 OX seedlings grown under SD conditions were exposed to filter papers soaked with MS solution containing $150 \mathrm{mM} \mathrm{NaCl}$. Seedlings were harvested separately after 1, 2, 4, and $8 \mathrm{~h}$, with $0 \mathrm{~h}$ as the control.

To observe seedling growth under osmotic-stress conditions, seeds were sown and grown on pure MS agar media for five days. For $\mathrm{NaCl}$ treatment, fully germinated seedlings were then transplanted to MS agar media supplemented with $\mathrm{NaCl}$ at concentrations of $0,140,150$, and $160 \mathrm{mM}$, and $\mathrm{FW}$ and photosynthetic activity $\left(F_{v} / F_{m}\right)$ of seedlings were measured after 10 or 15 days. For $\mathrm{LiCl}$ treatment, seedlings were transplanted to MS agar media containing $\mathrm{LiCl}$ at concentrations of $0,15,20$, and $25 \mathrm{mM}$, and seedling FW was measured after 15 days. For mannitol treatment, seedlings were transplanted to MS agar media containing mannitol at concentrations of $0,400,450$, and $500 \mathrm{mM}$, and seedling FW was measured 16 days after treatment. For freezing treatment, 3-week-old plants on MS agar media were kept at $-8^{\circ} \mathrm{C}$ for $0,1,2$, and $4 \mathrm{~h}$, and then allowed to recover for 5 days at $22{ }^{\circ} \mathrm{C}$.

To evaluate the response of mature AtRH17 OXs to $\mathrm{NaCl}$ exposure, 3-week-old plants cultivated under $\mathrm{LD}$ conditions were subjected to 0,350 , and $400 \mathrm{mM} \mathrm{NaCl}$ for three weeks, at 3-4-day intervals.

To assess the response of mature AtRH17 OXs to drought stress, 3-week-old plants cultivated under LD conditions were withheld watering for 12 days and then rewatered for five days.

\subsection{PS II Activity $\left(F_{v} / F_{m}\right)$ and Chlorophyll Content Measurement}

PS II activity $\left(F_{v} / F_{m}\right)$ of seedlings grown under SD conditions was measured using a FluorCam FC-800 (Photon Systems Instruments, Drasov, Czech), in accordance with the manufacturer's instructions.

PS II activity $\left(F_{v} / F_{m}\right)$ in the third or fourth rosette leaves of 6-week-old plants grown under LD conditions was measured using a Handy PEA chlorophyll fluorimeter (Hansatech, King's Lynn, UK), in accordance with the protocol described previously [50].

Measurement of chlorophyll content (SPAD value) in the fourth or fifth rosette leaves of 6-week-old plants grown under LD conditions was performed using an SPAD-502 plus chlorophyll meter (Konica Minolta, Inc., Tokyo, Japan), following the procedures described by Seok et al. [50].

\subsection{Histochemical Staining of Superoxide Production}

For histochemical staining of superoxide, 7-day-old seedlings grown under SD conditions were placed on filter papers soaked with 0,50 , and $100 \mathrm{mM} \mathrm{NaCl}$ for $2 \mathrm{~h}$ and incubated in $6 \mathrm{mM}$ nitro blue tetrazolium (NBT) solution for $2 \mathrm{~h}$ [53]. Chlorophyll was then removed by immersing the seedlings in $95 \%(v / v)$ ethanol at $50{ }^{\circ} \mathrm{C}$ for $2 \mathrm{~h}$. 


\subsection{RNA Extraction and RT-PCR Analysis}

Total RNA was extracted from seedlings and different organs of mature plants using an RNAqueous RNA Isolation Kit (Life Technologies, Carlsbad, CA, USA), supplemented with Plant RNA Isolation Aid (Life Technologies, Carlsbad, CA, USA). First-strand complementary DNA (cDNA) synthesis, semi-quantitative RT-PCR, and quantitative RT-PCR were performed following the procedures described by Seok et al. [50]. The primers used for PCR are listed in Supplementary Table S1.

\subsection{Multiple Sequence Alignment and Phylogenetic Analysis}

Conserved amino acid sequences of AtRH17 and its orthologs were aligned using ClustalX 2.1 software and manually corrected. MEGA 7.0.26 software was used to generate the phylogenetic tree based on a Maximum Likelihood analysis with a bootstrap of 1000.

\subsection{Subcellular Localization of the AtRH17-GFP Fusion Protein}

To examine the subcellular localization of AtRH17 in the protoplast of Arabidopsis, polyethylene glycol-mediated protoplast transformations were performed as described previously [54].

\subsection{Statistical Analysis}

IBM SPSS Statistics software version 23 (IBM Corp., Armonk, NY, USA) was used for statistical analysis.

Supplementary Materials: Supplementary materials can be found at http:/ / www.mdpi.com/1422-0067/19/12/ $3777 /$ s1.

Author Contributions: Conceptualization, D.-H.W.; Validation, L.V.N., H.-Y.S., and Y.-H.M.; Formal analysis, L.V.N. and H.-Y.S.; Investigation, L.V.N. and H.-Y.S.; Data curation, L.V.N. and H.-Y.S.; Writing一original draft preparation, L.V.N. and H.-Y.S.; Writing—review and editing, S.-Y.L.; Supervision, Y.-H.M.; Project administration, Y.-H.M.; Funding acquisition, Y.-H.M.

Funding: This work was supported by the National Research Foundation of Korea (NRF) grant funded by the Korea government (MSIT) (No. 2018R1A2B6006472 and No. 2017R1D1A1B03034337).

Conflicts of Interest: The authors declare no conflict of interest.

\section{Abbreviations}

$\begin{array}{ll}\text { ABA } & \text { Abscisic acid } \\ \text { AT } & \text { Activation tagging } \\ \text { CaMV } & \text { Cauliflower mosaic virus } \\ \text { DAG } & \text { Days after germination } \\ \text { LD } & \text { Long-day } \\ \text { MS } & \text { Murashige and Skoog } \\ \text { NBT } & \text { Nitro blue tetrazolium } \\ \text { OXs } & \text { Overexpressing transgenic plants } \\ \text { RH } & \text { RNA helicase } \\ \text { ROS } & \text { Reactive oxygen species } \\ \text { SD } & \text { Short-day }\end{array}$

\section{References}

1. Nakashima, K.; Takasaki, H.; Mizoi, J.; Shinozaki, K.; Yamaguchi-Shinozaki, K. NAC transcription factors in plant abiotic stress responses. Biochim. Biophys. Acta 2012, 1819, 97-103. [CrossRef] [PubMed]

2. Borkotoky, S.; Saravanan, V.; Jaiswal, A.; Das, B.; Selvaraj, S.; Murali, A.; Lakshmi, P.T.V. The Arabidopsis stress responsive gene database. Int. J. Plant Genom. 2013, 2013, 949564. [CrossRef] [PubMed]

3. Aubourg, S.; Kreis, M.; Lecharny, A. The DEAD box RNA helicase family in Arabidopsis thaliana. Nucleic Acids Res. 1999, 27, 628-636. [CrossRef] [PubMed] 
4. Cordin, O.; Banroques, J.; Tanner, N.K.; Linder, P. The DEAD-box protein family of RNA helicases. Gene 2006, 367, 17-37. [CrossRef] [PubMed]

5. Linder, P.; Jankowsky, E. From unwinding to clamping-The DEAD box RNA helicase family. Nat. Rev. Mol. Cell Biol. 2011, 12, 505-516. [CrossRef] [PubMed]

6. Owttrim, G.W. RNA helicases: Diverse roles in prokaryotic response to abiotic stress. RNA Biol. 2013, 10, 96-110. [CrossRef] [PubMed]

7. Xu, J.; Liu, C.; Li, M.; Li, H.; Hu, J.; Zhu, L.; Zeng, D.; Yang, Y.; Peng, Y.; Ruan, B.; et al. A rice DEAD-box RNA helicase protein, OsRH17, suppresses 16S ribosomal RNA maturation in Escherichia coli. Gene 2015, 555, 318-328. [CrossRef] [PubMed]

8. Linder, P.; Rocak, S. DEAD-box proteins: The driving forces behind RNA metabolism. Nat. Rev. Mol. Cell Biol. 2004, 5, 232-241. [CrossRef]

9. Fuller-Pace, F.V. DExD/H box RNA helicases: Multifunctional proteins with important roles in transcriptional regulation. Nucleic Acids Res. 2006, 34, 4206-4215. [CrossRef] [PubMed]

10. Nawaz, G.; Kang, H. Chloroplast- or mitochondria-targeted DEAD-box RNA helicases play essential roles in organellar RNA metabolism and abiotic stress responses. Front. Plant Sci. 2017, 8, 871. [CrossRef] [PubMed]

11. Tanner, N.K.; Cordin, O.; Banroques, J.; Doère, M.; Linder, P. The Q motif: A newly identified motif in DEAD box helicases may regulate ATP binding and hydrolysis. Mol. Cell 2003, 11, 127-138. [CrossRef]

12. Iost, I.; Dreyfus, M. DEAD-box RNA helicases in Escherichia coli. Nucleic Acids Res. 2006, 34, 4189-4197. [CrossRef] [PubMed]

13. Martin, R.; Straub, A.U.; Doebele, C.; Bohnsack, M.T. DExD/H-box RNA helicases in ribosome biogenesis. RNA Biol. 2013, 10, 4-18. [CrossRef] [PubMed]

14. Giraud, C.; Hausmann, S.; Lemeille, S.; Prados, J.; Redder, P.; Linder, P. The C-terminal region of the RNA helicase CshA is required for the interaction with the degradosome and turnover of bulk RNA in the opportunistic pathogen Staphylococcus aureus. RNA Biol. 2015, 12, 658-674. [CrossRef] [PubMed]

15. Banroques, J.; Cordin, O.; Doère, M.; Linder, P.; Tanner, N.K. Analyses of the functional regions of DEAD-box RNA “Helicases" with deletion and chimera constructs tested in vivo and in vitro. J. Mol. Biol. 2011, 413, 451-472. [CrossRef] [PubMed]

16. Gong, Z.; Dong, C.; Lee, H.; Zhu, J.; Xiong, L.; Gong, D.; Stevenson, B.; Zhu, J.K. A DEAD box RNA helicase is essential for mRNA export and important for development and stress responses in Arabidopsis. Plant Cell 2005, 17, 256-267. [CrossRef] [PubMed]

17. Gu, L.; Xu, T.; Lee, K.H.; Kang, H. A chloroplast-localized DEAD-box RNA helicase AtRH3 is essential for intron splicing and plays an important role in the growth and stress response in Arabidopsis thaliana. Plant Physiol. Biochem. 2014, 81, 309-318. [CrossRef] [PubMed]

18. Kanai, M.; Hayashi, M.; Kondo, M.; Nishimura, M. The plastidic DEAD-box RNA helicase 22, HS3, is essential for plastid functions both in seed development and in seedling growth. Plant Cell Physiol. 2013, 54, 1431-1440. [CrossRef] [PubMed]

19. Nishimura, K.; Ashida, H.; Ogawa, T.; Yokota, A. A DEAD box protein is required for formation of a hidden break in Arabidopsis chloroplast 23S rRNA. Plant J. 2010, 63, 766-777. [CrossRef] [PubMed]

20. Gong, Z.; Lee, H.; Xiong, L.; Jagendorf, A.; Stevenson, B.; Zhu, J.K. RNA helicase-like protein as an early regulator of transcription factors for plant chilling and freezing tolerance. Proc. Natl. Acad. Sci. USA 2002, 99, 11507-11512. [CrossRef] [PubMed]

21. Bond, A.T.; Mangus, D.A.; He, F.; Jacobson, A. Absence of Dbp2p alters both nonsense-mediated mRNA decay and rRNA processing. Mol. Cell. Biol. 2001, 21, 7366-7379. [CrossRef] [PubMed]

22. Huang, C.; Sie, Y.; Chen, Y.; Huang, T.; Lu, C. Two highly similar DEAD box proteins, OsRH2 and OsRH34, homologous to eukaryotic initiation factor 4AIII, play roles of the exon junction complex in regulating growth and development in rice. BMC Plant Biol. 2016, 16, 84. [CrossRef] [PubMed]

23. Lee, K.; Kang, H. Emerging roles of RNA-binding proteins in plant growth, development, and stress responses. Mol. Cells 2016, 39, 179-185. [CrossRef] [PubMed]

24. Stonebloom, S.; Burch-Smith, T.; Kim, I.; Meinke, D.; Mindrinoss, M.; Zambryski, P. Loss of the plant DEAD-box protein ISE1 leads to defective mitochondria and increased cell-to-cell transport via plasmodesmata. Proc. Natl. Acad. Sci. USA 2009, 106, 17229-17234. [CrossRef] [PubMed] 
25. Huang, C.; Huang, L.; Huang, J.; Wu, S.; Yeh, C.; Lu, C. A DEAD-box protein, AtRH36, is essential for female gametophyte development and is involved in rRNA biogenesis in Arabidopsis. Plant Cell Physiol. 2010, 51, 694-706. [CrossRef] [PubMed]

26. Liu, M.; Shi, D.Q.; Yuan, L.; Liu, J.; Yang, W.C. SLOW WALKER3, encoding a putative DEAD-box RNA helicase, is essential for female gametogenesis in Arabidopsis. J. Integr. Plant Biol. 2010, 52, 817-828. [CrossRef] [PubMed]

27. Hsu, Y.; Chen, Y.; Hsiao, Y.; Wang, B.; Lin, S.; Cheng, W.; Jauh, G.; Harada, J.J.; Wang, C. AtRH57, a DEAD-box RNA helicase, is involved in feedback inhibition of glucose-mediated abscisic acid accumulation during seedling development and additively affects pre-ribosomal RNA processing with high glucose. Plant J. 2014, 77, 119-135. [CrossRef] [PubMed]

28. Li, X.; Gao, X.; Wei, Y.; Deng, L.; Ouyang, Y.; Chen, G.; Li, X.; Zhang, O.; Wu, C. Rice APOPTOSIS INHIBITOR5 coupled with two DEAD-box adenosine $5^{\prime}$-triphosphate-dependent RNA helicases regulates tapetum degeneration. Plant Cell 2011, 23, 1416-1434. [CrossRef] [PubMed]

29. Liu, Y.; Imai, R. Function of plant DExD/H-box RNA helicases associated with ribosomal RNA biogenesis. Front. Plant Sci. 2018, 9, 125. [CrossRef] [PubMed]

30. Baruah, I.; Debbarma, J.; Boruah, H.P.D.; Keshavaiah, C. The DEAD-box RNA helicases and multiple abiotic stresses in plants: A systematic review of recent advantages and challenges. Plant Omics J. 2017, 10, $252-262$. [CrossRef]

31. Zhu, J.; Dong, C.; Zhu, J.K. Interplay between cold-responsive gene regulation, metabolism and RNA processing during plant cold acclimation. Curr. Opin. Plant Biol. 2007, 10, 290-295. [CrossRef] [PubMed]

32. Huang, C.; Shen, Y.; Huang, L.; Wu, S.; Yeh, C.; Lu, C. The DEAD-box RNA helicase AtRH7/PRH75 participates in pre-rRNA processing, plant development and cold tolerance in Arabidopsis. Plant Cell Physiol. 2016, 57, 174-191. [CrossRef] [PubMed]

33. Guan, Q.; Wu, J.; Zhang, Y.; Jiang, C.; Liu, R.; Chai, C.; Zhu, J. A DEAD box RNA helicase is critical for pre-mRNA splicing, cold-responsive gene regulation, and cold tolerance in Arabidopsis. Plant Cell 2013, 25, 342-356. [CrossRef] [PubMed]

34. Kant, P.; Kant, S.; Gordon, M.; Shaked, R.; Barak, S. Stress Response Suppressor1 and Stress Response Suppressor2, two DEAD-box RNA helicases that attenuate Arabidopsis responses to multiple abiotic stresses. Plant Physiol. 2007, 145, 814-830. [CrossRef] [PubMed]

35. Khan, A.; Garbelli, A.; Grossi, S.; Florentin, A.; Batelli, G.; Acuna, T.; Zolla, G.; Kaye, Y.; Paul, L.K.; Zhu, J.K.; et al. The Arabidopsis STRESS RESPONSE SUPPRESSOR DEAD-box RNA helicases are nucleolar- and chromocenter-localized proteins that undergo stress-mediated relocalization and are involved in epigenetic gene silencing. Plant J. 2014, 79, 28-43. [CrossRef] [PubMed]

36. Kim, J.S.; Kim, K.A.; Oh, T.R.; Park, C.M.; Kang, H. Functional characterization of DEAD-box RNA helicases in Arabidopsis thaliana under abiotic stress conditions. Plant Cell Physiol. 2008, 49, 1563-1571. [CrossRef] [PubMed]

37. Li, D.; Liu, H.; Zhang, H.; Wang, X.; Song, F. OsBIRH1, a DEAD-box RNA helicase with functions in modulating defence responses against pathogen infection and oxidative stress. J. Exp. Bot. 2008, 59, 2133-2146. [CrossRef] [PubMed]

38. Sanan-Mishra, N.; Pham, X.H.; Sopory, S.K.; Tuteja, N. Pea DNA helicase 45 overexpression in tobacco confers high salinity tolerance without affecting yield. Proc. Natl. Acad. Sci. USA 2005, 102, 509-514. [CrossRef] [PubMed]

39. Shivakumara, T.N.; Sreevathsa, R.; Dash, P.K.; Sheshshayee, M.S.; Papolu, P.K.; Rao, U.; Tuteja, N.; UdayaKumar, M. Overexpression of pea DNA helicase 45 (PDH45) imparts tolerance to multiple abiotic stresses in chili (Capsicum annuum L.). Sci. Rep. 2017, 7, 2760. [CrossRef] [PubMed]

40. Jeong, D.H.; An, S.; Kang, H.G.; Moon, S.; Han, J.J.; Park, S.; Lee, H.S.; An, K.; An, G. T-DNA insertional mutagenesis for activation tagging in rice. Plant Physiol. 2002, 130, 1636-1644. [CrossRef] [PubMed]

41. Marsch-Martinez, N.; Greco, R.; Van Arkel, G.; Herrera-Estrella, L.; Pereira, A. Activation tagging using the En-I maize transposon system in Arabidopsis. Plant Physiol. 2002, 129, 1544-1556. [CrossRef] [PubMed]

42. Ito, T.; Meyerowitz, E.M. Overexpression of a gene encoding a cytochrome P450, CYP78A9, induces large and seedless fruit in Arabidopsis. Plant Cell 2000, 12, 1541-1550. [CrossRef] [PubMed] 
43. Lee, S.Y.; Seok, H.Y.; Tarte, V.N.; Woo, D.H.; Le, D.H.; Lee, E.H.; Moon, Y.H. The Arabidopsis chloroplast protein S-RBP11 is involved in oxidative and salt stress responses. Plant Cell Rep. 2014, 33, 837-847. [CrossRef] [PubMed]

44. Ashraf, M.; Harris, P.J.C. Potential biochemical indicators of salinity tolerance in plants. Plant Sci. 2004, 166, 3-16. [CrossRef]

45. Ashraf, M. Biotechnological approach of improving plant salt tolerance using antioxidants as markers. Biotechnol. Adv. 2009, 27, 84-93. [CrossRef] [PubMed]

46. Wang, T.; McFarlane, H.E.; Persson, S. The impact of abiotic factors on cellulose synthesis. J. Exp. Bot. 2016, 67, 543-552. [CrossRef] [PubMed]

47. Nakashima, K.; Ito, Y.; Yamaguchi-Shinozaki, K. Transcriptional regulatory networks in response to abiotic stresses in Arabidopsis and grasses. Plant Physiol. 2009, 149, 88-95. [CrossRef] [PubMed]

48. Barak, S.; Singh Yadav, N.; Khan, A. DEAD-box RNA helicases and epigenetic control of abiotic stress-responsive gene expression. Plant Signal. Behav. 2014, 9, e977729. [CrossRef] [PubMed]

49. Tarte, V.N.; Seok, H.Y.; Woo, D.H.; Le, D.H.; Tran, H.T.; Baik, J.W.; Kang, I.S.; Lee, S.Y.; Chung, T.; Moon, Y.H. Arabidopsis Qc-SNARE gene AtSFT12 is involved in salt and osmotic stress responses and $\mathrm{Na}^{+}$accumulation in vacuoles. Plant Cell Rep. 2015, 34, 1127-1138. [CrossRef] [PubMed]

50. Seok, H.Y.; Woo, D.H.; Nguyen, L.V.; Tran, H.T.; Tarte, V.N.; Mehdi, S.M.M.; Lee, S.Y.; Moon, Y.H. Arabidopsis AtNAP functions as a negative regulator via repression of AREB1 in salt stress response. Planta 2017, 245, 329-341. [CrossRef] [PubMed]

51. Höfgen, R.; Willmitzer, L. Storage of competent cells for Agrobacterium transformation. Nucleic Acids Res. 1988, 16, 9877. [CrossRef] [PubMed]

52. Clough, S.J.; Bent, A.F. Floral dip: A simplified method for Agrobacterium-mediated transformation of Arabidopsis thaliana. Plant J. 1998, 16, 735-743. [CrossRef] [PubMed]

53. Flohé, L.; Otting, F. Superoxide dismutase assays. Methods Enzymol. 1984, 105, 93-104. [CrossRef] [PubMed]

54. Sheen, J. Signal transduction in maize and Arabidopsis mesophyll protoplasts. Plant Physiol. 2001, 127, 1466-1475. [CrossRef] [PubMed] 